\title{
Analytical and numerical analysis of the tire tightening system of a cement kiln
}

\author{
S. El Fakkoussi ${ }^{1} \cdot$ H. Moustabchir ${ }^{2} \cdot$ A. Elkhalfi ${ }^{1}$ - C. I. Pruncu ${ }^{3,4}{ }^{(1)}$
}

Received: 16 May 2019 / Accepted: 25 May 2019 / Published online: 3 June 2019

(c) The Author(s) 2019

\begin{abstract}
The rotary cement kiln forms a major part of any cement works. The kiln is a large cylindrical structure where the raw materials are brought together and heated to form clinker, the base material of cement. To ensure production plant reliability and product quality an understanding and evaluation of the kiln design parameters is of paramount importance. This paper presents a solution for evaluating the mechanical strength of the shims, vital components in the drive system. These parts transmit the rotational drive to the kiln drum, and are subject to large mechanical and thermal stresses. The results of this study enable a reliable plan for preventive maintenance of the kiln furnaces to be developed. The methodology employed detects the mechanical and thermal stresses distributed on the surface of the shim while the working cycle are active, and uses both mechanical theory and numerical simulation by the Finite Elements Method (FEM) under the ANSYS software. The numerical results provide an authoritative guide to the accurate prediction of the optimal preventative maintenance interval for the rotary cement kilns drive element.
\end{abstract}

Keywords Rotary kiln $\cdot$ Maintenance time $\cdot$ Binder $\cdot$ Casing $\cdot$ Numerical simulation $\cdot$ ANSYS

\section{Introduction}

In recent years, the cement industry has made significant investments in increasing and diversifying production in order to satisfy growing market demand. Lafarge Holcim [1], the international leader in materials construction, is part

$凶$ C. I. Pruncu

c.pruncu@imperial.ac.uk

S. El Fakkoussi

said.elfakkoussi@gmail.com

H. Moustabchir

hmoustabchir@hotmail.com

A. Elkhalfi

aelkhalfi@gmail.com

1 Mechanical Engineering Laboratory Faculty of Science and Technology, Fez, Morocco

2 Laboratory of Systems Engineering and Applications (LISA), National School of Applied Sciences of Fez, Fez, Morocco

3 Department of Mechanical Engineering, Imperial College London, Exhibition Road, London SW7 2AZ, UK

4 Department of Mechanical Engineering, School of Engineering, University of Birmingham, Birmingham B15 2TT, UK of the move to a sustainable development strategy aimed at reducing environmental impact in the face of strong competition and the increasing demand for building materials. They produce cement that is a hydraulic binder, a mineral powder of greyish appearance, obtained by grinding and baking a mixture of limestone and clay at $1450{ }^{\circ} \mathrm{C}$. The main product (material) of this process, called clinker, is formed of a combination of lime, silica, alumina and ferric oxide.

As a general rule, the furnace comprises a group of pipelines (that are in permanent rotation allowing the displacement of the material) made of low-carbon steel connected end to end, forming a global entity called a casing (shell). The casing (shell) of the rotary furnace consists of several sections of different sizes assembled by welding and coated with refractory bricks. The assembly is supported and driven in rotation by three roll riding tyre, or hoops, as is depicted on the Fig. 1.

The furnace is a massive and strong structure but cannot tolerate any type of geometrical defects. In fact, the biggest furnaces are most susceptible. To allow for thermal expansion and mechanical loading and deformation a shim element is fitted between the riding tyre and the casing (shell). This shim element is liable to damage due to the thermal expansion of 


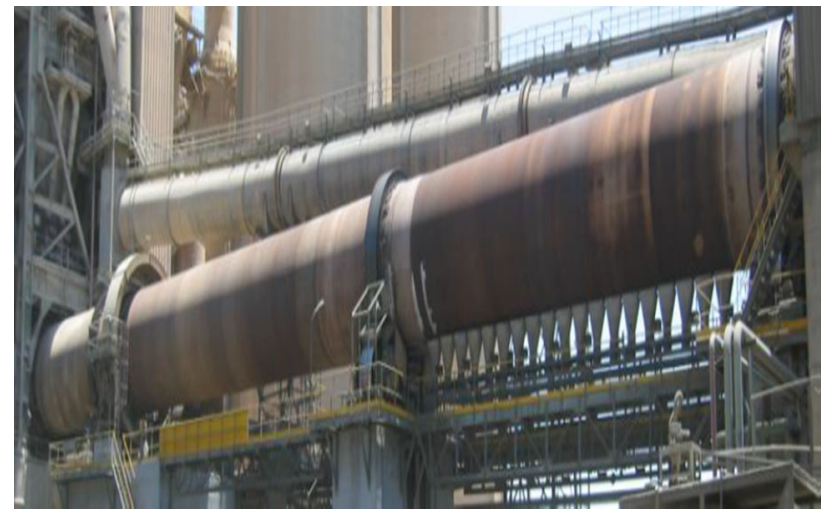

Fig. 1 A typical rotary kiln

the elements (casing and riding tyre), but also because of the weight of the kiln and its contents.

Indeed, the rotation of the riding tyre may cause its wear as well as that of the wedges, shims and lateral hoops (see Fig. 2). When the wear of the shims becomes too great, the casing (shell) may become critically deformed, which causes a loss of the bricks [2]. The shims are evenly distributed around the casing (shell) and serve to hold the riding tyre in a fixed rotational path around the furnace. They must, however, ensure a functional clearance of $11 \mathrm{~mm}$, to prevent thermal expansion of the casing (shell) generating permanent deformation.

In the case examined, the bandage riding tyre currently contains a transverse crack that extends almost to the two ends of the riding tyre. The shims, on the other hand, tend to detach from the casing (shell) and to destabilize the rotation of the riding tyre. Thus, the dimensions of the shims, their method of attachment and their component material must be carefully studied in order to avoid distortion of the shell that may be critical to riding tyre stability and have a further impact on the fracture resistance of the structure. The finite element software ANSYS was engaged to analyse the structure stress and the thermal stress distribution in the cylinder. The analysis results are helpful in the design and optimization of the rotary kiln cylinder [3-5]. The predicted results of outer kiln wall temperature agree well with measurements [6]. The results assist in maintaining the reliability of the cement kiln so as to ensure its continuous operation $24 \mathrm{~h}$ a day [7].

\section{Component geometry and mechanical characteristics}

\subsection{Geometry}

A rotary kiln is the key rotating machine used in the production of cement. Similar large rotating machines are used in other chemical and metallurgical industries. The tubular geometry of the furnace is represented in Fig. 3. The overall dimensions of the kiln are length of 63 meters and internal diameter 4 meters (Table 1). In evaluating the operation state of the kiln, it is important to measure the straightness deviation and surface deformation of kiln cylinder as they are important physical indictors of kiln condition [8].

In order to determine globally the reaction forces generated on the supports, it was used the Resistance Calculation Software (RDM6). A sketch of these reaction and forces are plotted in Fig. 4.

In this study, we consider the performance of the shim element used to transmit forces between the kiln drum and the supporting hoops. The geometry of the shim component was
Fig. 2 The riding tyre and timing system during deformation of shim parts

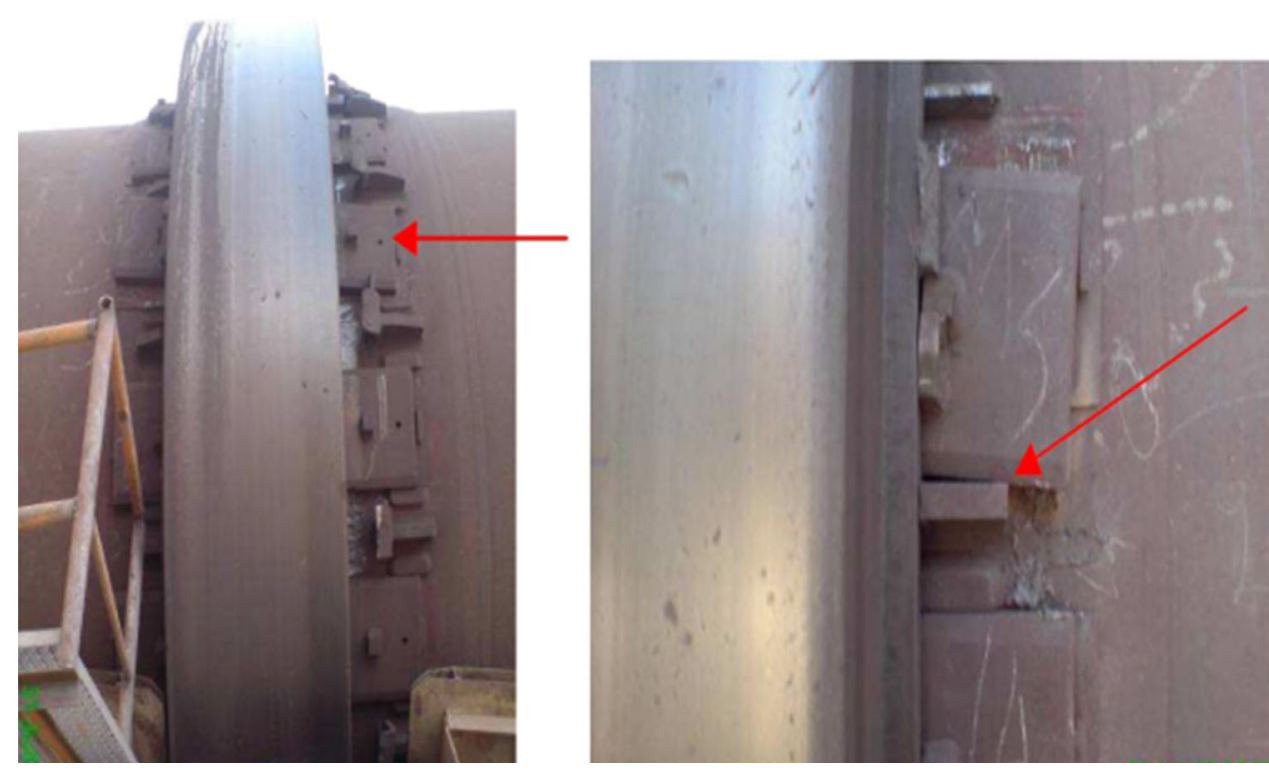


Fig. 3 A simplified arrangement of the furnace geometry

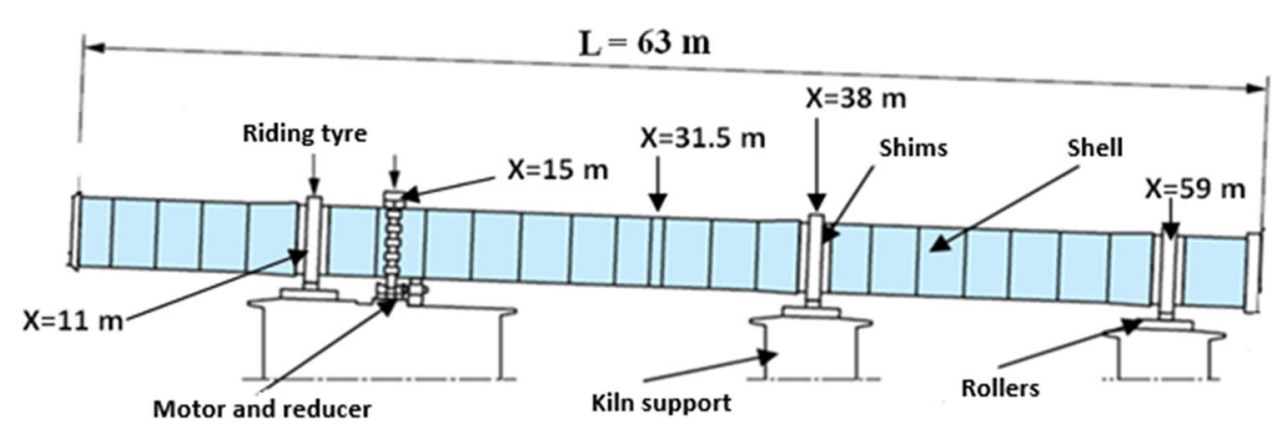

Table 1 Geometric and mechanical characteristics of the Kiln

\begin{tabular}{ll}
\hline Kiln length & $63 \mathrm{~m}$ \\
Kiln internal diameter & $4.00 \mathrm{~m}$ \\
Kiln external diameter & $4.15 \mathrm{~m}$ \\
Angle inclination & $1.718^{\circ}$ \\
Rotation Frequency & $3 \mathrm{~T} / \mathrm{min}$ \\
Number of supports & 3 \\
Weight of rotating cement & $136.96 \mathrm{~T}$ \\
Total weight oven steel & $184.49 \mathrm{~T}$ \\
Total weight of kiln bricks & $371.41 \mathrm{~T}$ \\
Inner radius of the ring & $2132 \mathrm{~mm}$ \\
\hline
\end{tabular}

represented by a 3D CAD model developed in SolidWorks. This model showing the geometrical and dimensional representation is shown in Fig. 5. This model was ported into the ANSYS F.E. package in order to evaluate the shim performance under external loading conditions.

\subsection{Material}

The shim component is made of a material A42CP [9]. The mechanical characteristics are given in the Table 2.

\section{Assessment of working conditions}

\subsection{Analytical evaluation}

\subsubsection{Mechanical and thermal study}

The cylindrical kiln structure is a loose fit within the kiln tyre, and can be treated as a simply supported beam. The kiln shell at inlet and kiln outlet are unsupported. Reaction at the tyre under loading is considered [10]. The force applied to the shim and the reaction forces (Table 3 ) at the bearings can be calculated using the following formula $[11,12]$.

$Q=\frac{2 \cdot R_{2} \cdot \cos (\varphi)}{R \pi}$

with $(\varphi)=5 \pi / 6, R$ inner radius of the ring.

Figure 6 shows general arrangement of tyre and rollers. $Q$ and $R_{2}$ respectively are the force applied to the shim and the reaction force at bearing 2 of the furnace.

The resulting mechanical and thermal forces acting on the shims are represented in Fig. 7.

A simplified loading model was generated: the cement mixture is assumed to be symmetrically distributed around

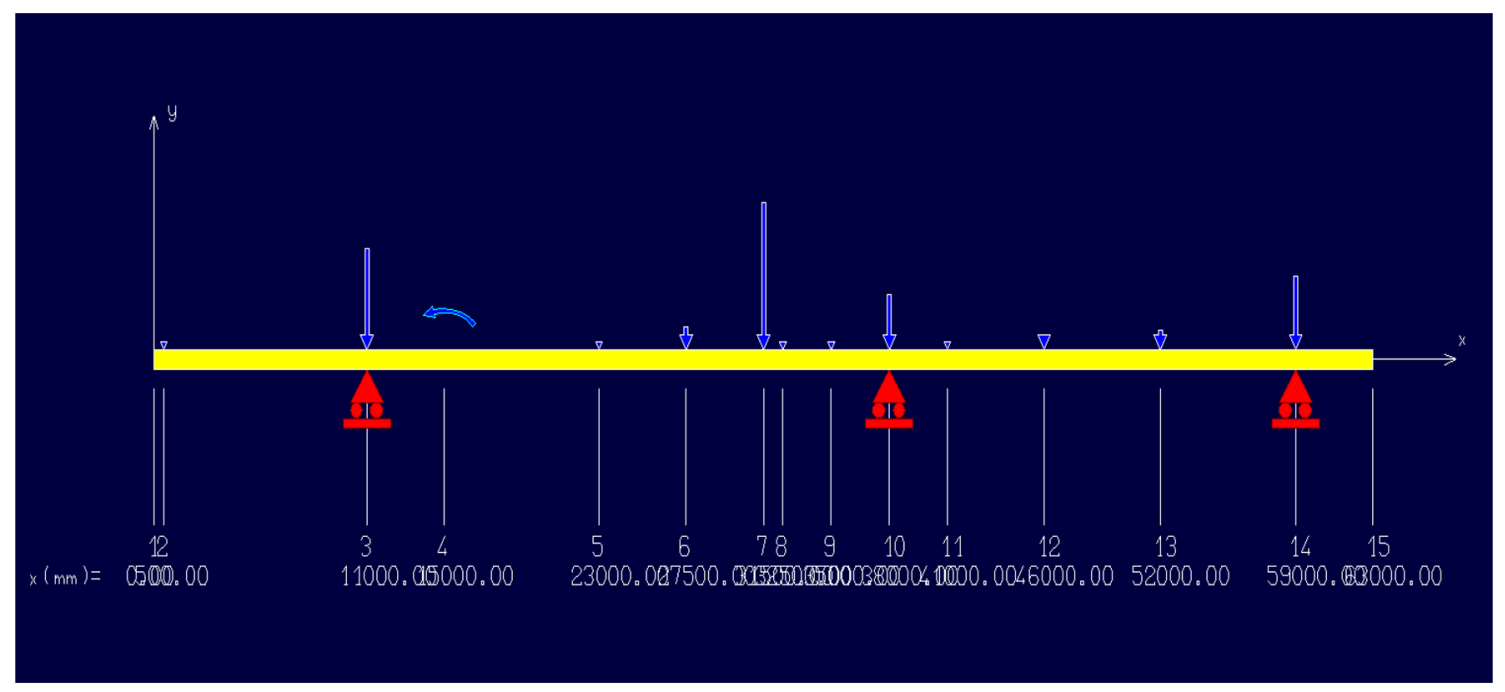

Fig. 4 Distribution of forces in the oven applied to the supports 


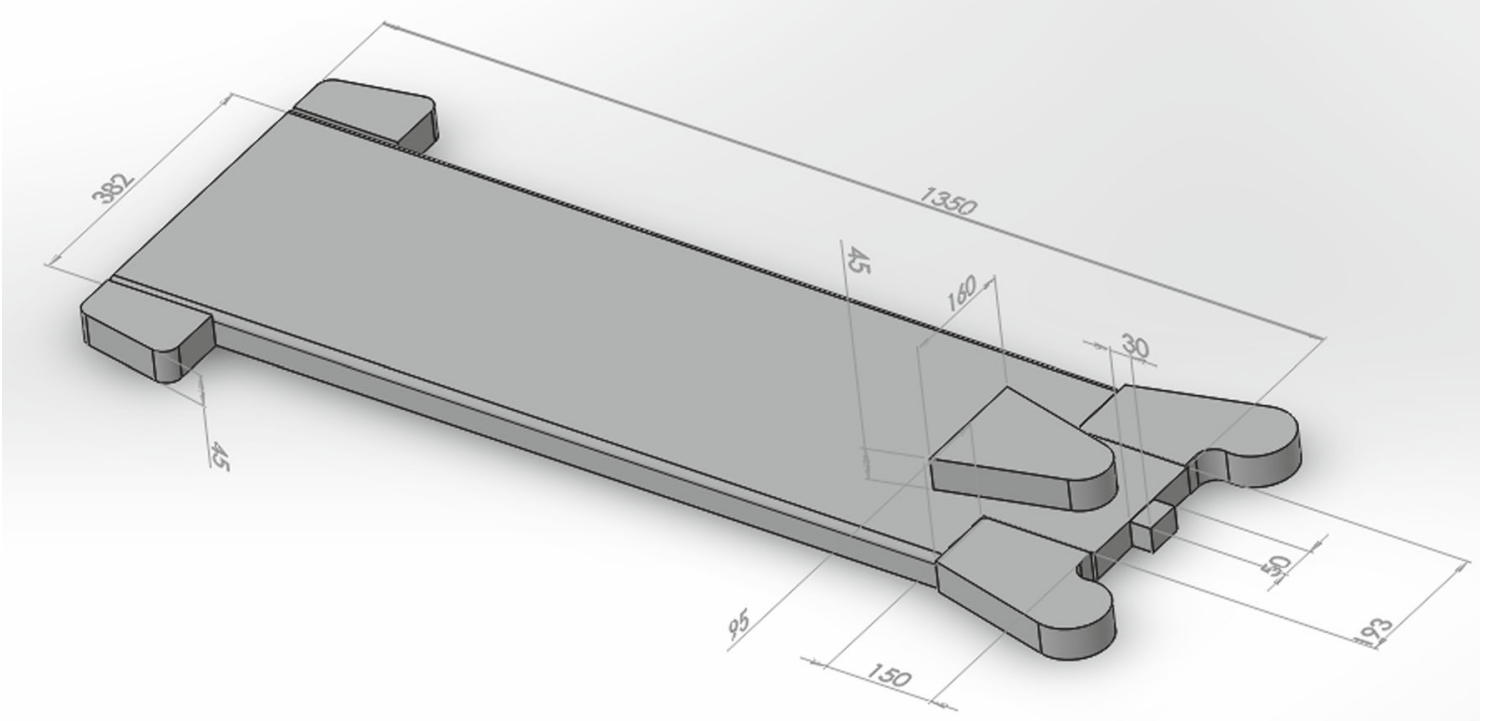

Fig. 5 Geometrical sketch of a shim, values in $\mathrm{mm}$

Table 2 Mechanical characteristics of A42CP [9]

\begin{tabular}{ll}
\hline Material properties & Values \\
\hline Young modulus & $210,000 \mathrm{MPa}$ \\
Poisson ratio & 0.3 \\
Yield strength & $250 \mathrm{MPa}$ \\
Tensile strength & $420 \mathrm{MPa}$ \\
Density & $7850 \mathrm{~kg} / \mathrm{m}^{3}$ \\
\hline
\end{tabular}

Table 3 Forces determined for the kiln supports

\begin{tabular}{ll}
\hline $\begin{array}{l}\text { Reaction forces }\left(\mathrm{R}_{1}\right) \\
\quad \text { at }(\mathrm{X}=11 \mathrm{~m})\end{array}$ & $2.23 * 10^{3} \mathrm{kN}$ \\
$\begin{array}{l}\text { Reaction forces }\left(\mathrm{R}_{2}\right) \\
\quad \text { at }(\mathrm{X}=38 \mathrm{~m})\end{array}$ & $4.84 * 10^{3} \mathrm{kN}$ \\
$\begin{array}{l}\text { Reaction forces }\left(\mathrm{R}_{3}\right) \\
\quad \text { at }(\mathrm{X}=59 \mathrm{~m})\end{array}$ & $0.76^{*} 10^{3} \mathrm{kN}$ \\
Torque $(\mathrm{X}=15 \mathrm{~m})$ & $670.23 \mathrm{kN} \mathrm{m}$ \\
\hline
\end{tabular}

the vertical axis of the kiln. This means that load weight of material is evenly distributed over each roller [11].

The mechanical and thermal loads applied to the shim are:

$$
\sigma_{1}=\frac{Q}{S}
$$

where $S$ load bearing area of shim, $Q$ load on the shim (Eq. 1).

For the case considered:

$Q=1440 \mathrm{KN}$ With $S=723 * 382$ and $S=276,186 *$ $10^{3} \mathrm{~mm}^{2}$.

Thus, the stress applied to the outer surface of the shim, its equal to a value $\sigma_{1}=5.21 \mathrm{MPa}$.

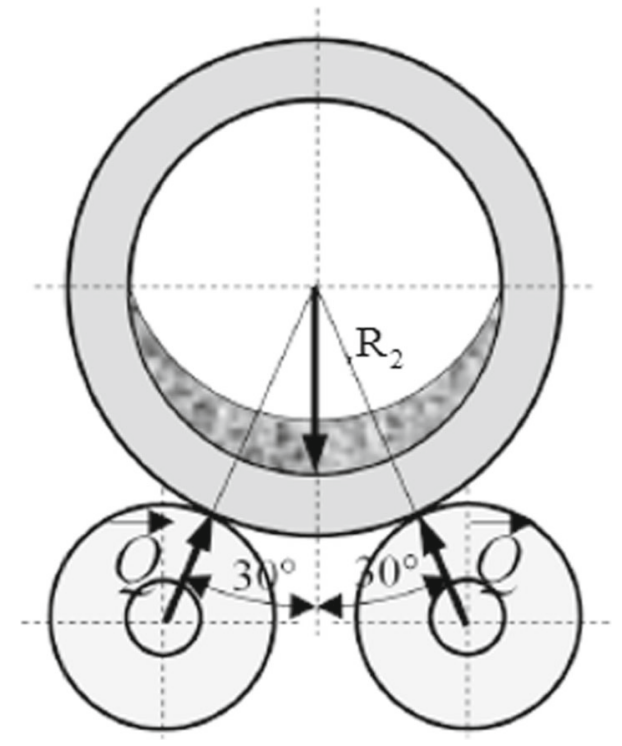

Fig. 6 Shows general arrangement of tyre and rollers. Q and $R_{2}$ respectively are the force applied to the shim and the reaction force at bearing two of the furnace

The weight of the tyre that translates as an axial force over the upper wing of the shim generates a stress equal $\sigma_{2}=1.11 \mathrm{MPa}$.

The shim is in contact with the ring, on the ring side temperature is around $275^{\circ} \mathrm{C}$. It has to be measured using infrared thermometer and with the welded-on the shell at a temperature of $300{ }^{\circ} \mathrm{C}$. The temperature difference is generated due of thermal stress that generates a loading of $\sigma_{3}=173.25 \mathrm{MPa}$ (Fig. 8). 
Fig. 7 Representation of forces applied on the shim

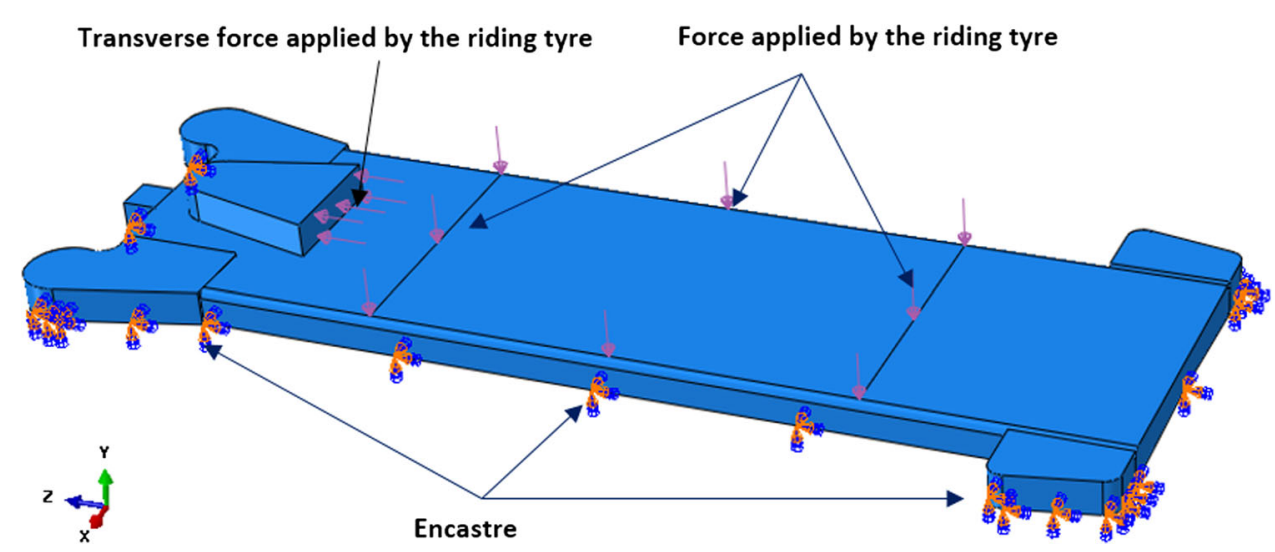

Fig. 8 Temperature distribution at Shim level

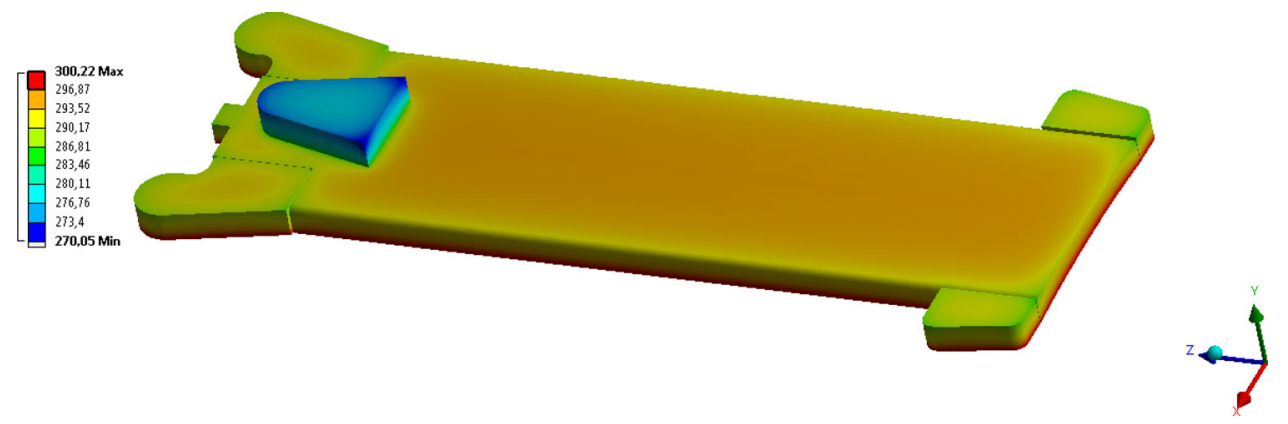

The result confirms that the minimum criteria of maintenance can be predicted successfully.

$\sigma_{\max }\left(\max \left(\sigma_{1}, \sigma_{2}, \sigma_{3}\right)\right)<R_{e}$

$\sigma_{\max }=173.25 \mathrm{MPa}$ is maximum stress applied to the shim, $R_{e}=250 \mathrm{MPa}$ is the limit of elasticity of material A42CP.

\subsubsection{Fatigue study}

Each shim, when performing a single turn of the furnace, is subjected to intermittent compression stress between the tire and the casing (shell) because it is getting in the contact with the roller 1 and then with the roller 2 .

There, $\sigma^{\prime}{ }_{a}$ and $\sigma_{m}^{\prime}$ are the equivalent constraints of Von Misses developed from the alternating and average components, ascribed as:

$\sigma_{a}^{\prime}=\sigma_{1}, \quad \sigma_{a}^{\prime}=5.21 \mathrm{MPa}$

$\sigma_{m}^{\prime}=\sqrt{\sigma_{3}^{2}+3 \sigma_{2}^{2}}, \quad \sigma_{m}^{\prime}=173 \mathrm{MPa}$

$\sigma=\sigma_{m}^{\prime}+\sigma_{a}^{\prime} \cdot \sin (\omega \cdot t)$

Further, the endurance limit $\left(\sigma_{D}\right)$ that is generated in the rotational bending were calculated integrating some assumption that was developed by using specific equations, such as:

$$
R_{M}<800 \mathrm{MPa} ; \sigma_{D}=R_{M}\left(0.56-1.4 * 10^{-4} R_{M}\right)
$$

$800 \mathrm{MPa}<R_{M}<1300 \mathrm{MPa} ; \sigma_{D}$

$$
=R_{M}\left(0.57-1.2 * 10^{-4} R_{M}\right)
$$

$1300 \mathrm{MPa}<R_{M} ; \quad \sigma_{D}=R_{M}\left(0.56-1.4 * 10^{-4} R_{M}\right)$

$\sigma_{D}=210.05 \mathrm{MPa}$

However, in order to determine the structure fatigue life accurately it requires carefully examination of all stress states involved in the process. Further, variations can occurs because of geometry imperfection (notches, holes...) that one generate reduction of the fatigue limits. A paramount importance should be dedicated to prediction of life expectancy in relationship to its structural details.

Therefore, were introduced some correction factors such as [13]:

$\sigma_{D}^{\prime}=k_{a} \times k_{b} \times k_{c} \times k_{d} \times \sigma_{D}$

$\sigma_{D}^{\prime}$ is the endurance limit corrected, $k_{a}$ surface finish factor, $k_{b}$ size effect factor, $k_{c}$ reliability factor, $k_{d}$ factor of the effect of temperature.

$\sigma_{D}^{\prime}=k_{a} \times k_{b} \times k_{c} \times k_{d} \times \sigma_{D}$

$\sigma_{D}^{\prime}=0.72 \times 0.75 \times 0.897 \times 0.6 \times 210.5$

$\sigma_{D}^{\prime}=61.17 \mathrm{MPa}$ 
Fig. 9 Shim model showing the FE mesh used in the analysis

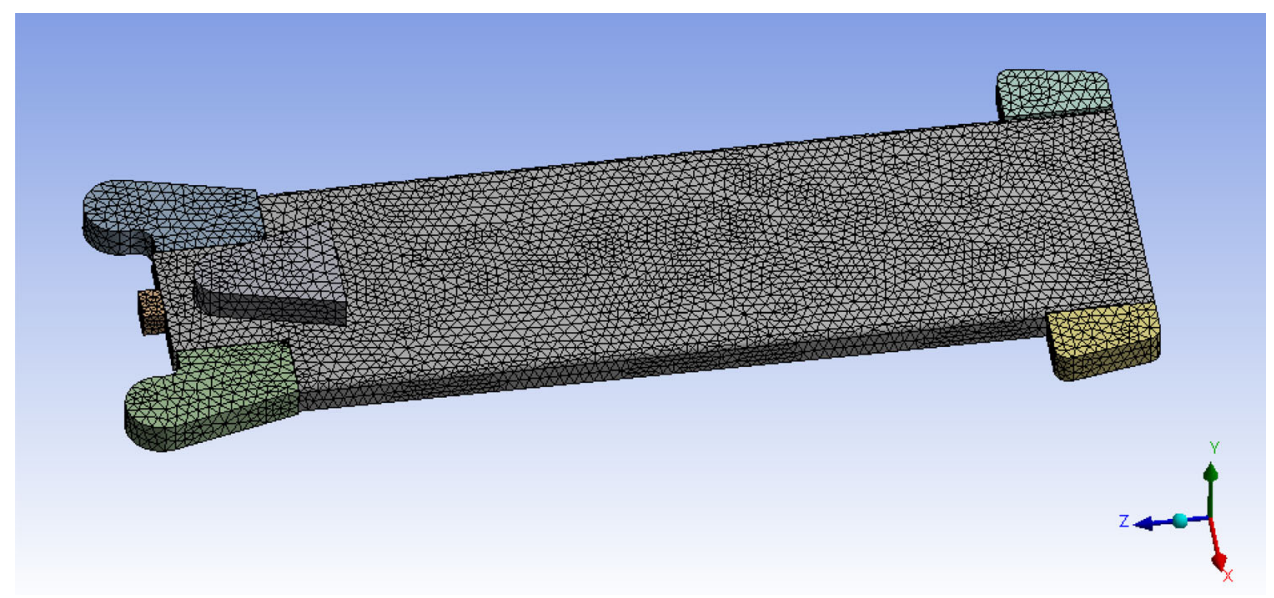

Here, the security factor were determined using several methods:

- method Goodman [14]:

$$
\begin{aligned}
& F S=1 /\left(\frac{\sigma_{a}^{\prime}}{\sigma_{D}^{\prime}}+\frac{\sigma_{m}^{\prime}}{R_{m}}\right) \\
& F S=1.68
\end{aligned}
$$

- method Soderbergh [14]:

$$
\begin{aligned}
& F S=1 /\left(\frac{\sigma_{a}^{\prime}}{\sigma_{D}^{\prime}}+\frac{\sigma_{m}^{\prime}}{\mathrm{R}_{e}}\right) \\
& F S=1.14
\end{aligned}
$$

- method gerber [14]:

$$
F S=1 /\left(\frac{\sigma_{a}^{\prime}}{\sigma_{D}^{\prime}}+\left(\frac{\sigma_{m}^{\prime}}{\mathrm{R}_{m}}\right)^{2}\right)
$$

$F S=2.28$

In the end, were calculated the life span of the shim in terms of the number of cycles (hours). Later on, it was fitted against the maximum stress using the Wöhler curve [13] and the results were obtained as:

$$
\begin{aligned}
t(h) & =\frac{N_{C y c l}}{T(t r / m i n)} \times \frac{1 \text { tour } / \mathrm{min}}{60 \mathrm{~min} / \mathrm{h}} \\
t(h) & =\frac{2.5 \times 10^{7} \mathrm{cycl}}{3} \times \frac{1 \mathrm{tour} / \mathrm{min}}{60 \mathrm{~min} / \mathrm{h}} ; t=1.3810^{5} \mathrm{~h}
\end{aligned}
$$

The actual working condition permits to estimate a safety life of the entire structure for around 15 years. Moreover, taking into account that the elastic limit is more the $15 \%$ higher compare to the endurance limit determined; in reality the lifespan of this component can be extended to more than 15 years with will provide benefits as well in terms of economic aspects.

\subsection{Numerical simulation}

Verification of the results obtained by theoretical calculation is an important and necessary phase. Hence the importance of numerical simulations which are able to exploit the increasingly powerful processors and simulation software available. By undertaking a check under ANSYS software it is possible to analyse and visualise the concentration of stresses and identify the most stressed parts. This allows the modifications necessary to ensure the proper functioning of this system to be determined and evaluated.

Figure 9 shows the finite element model adopted for solving the problem. This contains 99,499 nodes and 62,424 elements.

\subsubsection{Results}

Numerical analysis was carried out using ANSYS software [15]. The numerical analysis represents a solution more realistic of a kiln-tyre system that may reveal smaller compressive stresses in the contact region compared to the analytical predictions [16]. After the 3D geometry model is built (see for reference Fig. 5), it can be imported into the analysis module to establish the finite element model. The finite element model mainly comprises the geometric model containing the parts of a shim body, the definition of material parameters, and the finite element mesh generation [17].

The loading condition considered is that shown in Fig. 7. The thermal condition imposed is that where the shim inner surface reach around $300{ }^{\circ} \mathrm{C}$, with all other surface being in free air at $275^{\circ} \mathrm{C}$.

After analysing the result obtained by the threedimensional numerical model embedded into ANSYS it is 
Fig. 10 A picture of distribution of thermo mechanical stresses in the shim
Fig. 11 A picture of the displacements along the Y-axis in the shim/hold
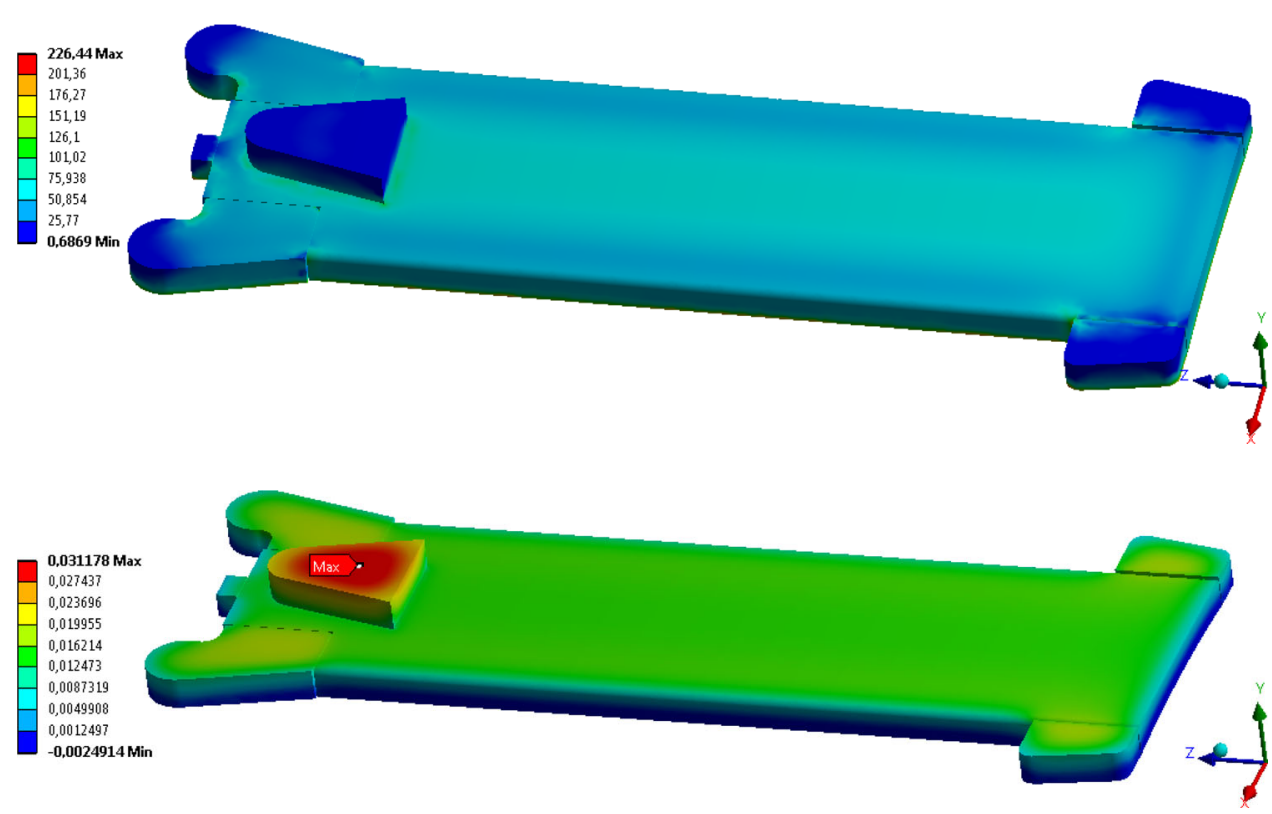

possible to verify the validity of the stresses used to predict the maintenance period.

Figure 10 shows the maximum loading condition on shim part. The influence of mechanical stresses is low compared to thermal stresses. The equivalent maximum stress of Von Mises $\sigma_{V M}=226.44 \mathrm{MPa}$ and the value of the analytical method $\sigma_{\max }=173.25 \mathrm{MPa}$ remains well below the elastic limit Yield Stress of $R_{e}=250 \mathrm{MPa}$.

The resulting displacements of the shim are shown in Fig. 11. Displacements along the Y axis are low at the bottom of the shim due to fixation and increase towards the head where the value at the highest points of the upper part of the shim is equal to $0.031 \mathrm{~mm}$. Remember that the calculation of the displacement in the hold is done by the numerical method (i.e. the software finite elements ANSYS).

\section{Conclusion}

A reliable calibration analysis of a system model was done. The results obtained by analytical and numerical methods are comparable and reflect the documented results from experimental and theoretical engineering judgment and experience [18]. The strategy applied has advantages due to the use of a detailed (3D) FEA model to reflect the actual service conditions and geometry. As a result of this work, it is further proposed to study the weld bead between the shims and the shroud. The objective is to deduce the constraints applied to the shim and to model the operating conditions of within the context of determining the preventive maintenance requirements of the cement kiln. And to add a complementary assessment to the entire plant will be worth to impose an extended plan that should incorporate a validated technique used to build extremely reliable devices based on the optimal plan by estimation a constant-stress of an accelerated life tests [19].

Open Access This article is distributed under the terms of the Creative Commons Attribution 4.0 International License (http://creativecomm ons.org/licenses/by/4.0/), which permits unrestricted use, distribution, and reproduction in any medium, provided you give appropriate credit to the original author(s) and the source, provide a link to the Creative Commons license, and indicate if changes were made.

\section{References}

1. https://en.wikipedia.org/wiki/Lafarge_(company). Accessed 25 Nov 2018

2. Janati, K.I.: Hot rotary kiln deformability for cement plant, experimentation, and numerical simulation. IOSR J. Mech. Civ. Eng. 14(01), 14-22 (2017)

3. Jia, X.Z., Zhang, Z.W., Liu, H.B.: Finite element analysis of rotary kiln cylinder. Adv. Mater. Res. 228-229, 174-178 (2011)

4. Shen, Y.-P., Wang, S.-L., Li, X.-J., Dhillon, B.S.: Multiaxial fatigue life prediction of kiln roller under axis line deflection. Appl. Math. Mech. 31(2), 205-214 (2010)

5. Song, X.Y., Fan, Q.: The analysis of rotary kiln thermal characteristics based on ANSYS and FLUENT. Adv. Mater. Res. 834-836, 1523-1528 (2014)

6. Li, G., Liu, Z., Jiang, G., Liu, H., Xiong, H.: Numerical simulation of the influence factors for rotary kiln in temperature field and stress field and the structure optimization. 7 (2015)

7. Tharoon, T.: Analysis of rotary kiln support roller by using analytical method and FEA software. Int. J. Res. Appl. Sci. Eng. Technol. (IJRASET) 4(XII) (2016)

8. Zheng, K., Zhang, Y., Zhao, C., Liu, L.: Rotary kiln cylinder deformation measurement and feature extraction based on EMD method. Eng. Lett. 23, 283-291 (2015)

9. A42CP (AFNOR NFA) Worldwide equivalent grades. https:// perma.cc/2EB4-73MN http://www.steelnumber.com/en/ 
equivalent_steel_iron_eu.php?zname_id=2806. Accessed 07 Dec 2018

10. Deshpande, V., Dhekhane, A.: Contribution to kiln tyre contact stress analysis. Int. J. Innov. Res. Sci. 3(2), 9500-9504 (2014)

11. Alhajjaji, M., Boubeker, B., Eljoumani, S., Zamma, A., Idiri, M., Atik, H.: Development of a monitoring scheme for preventive maintenance of the cement machinery. SpringerPlus 5, 253 (2016)

12. Žiga, A., Karač, A., Vukojević, D.: Analytical and numerical stress analysis of the rotary kiln ring. Tehnički Vjesnik 20, 941-946 (2013)

13. Ibrahim, R.A.: Fatigue Life and Reliability Assessment, in Handbook of Structural Life Assessment, pp. 359-429. Wiley, Chichester (2017)

14. Taylor, D.: The Theory of Critical Distances: A New Perspective in Fracture Mechanics. Elsevier, Amsterdam (2007)

15. https://www.ansys.com/About-ANSYS/news-center/12-08-11ANSYS-14-0-Delivers-Capabilities-for-Improved-Efficiency. Accessed 25 Nov 2018
16. Ingawale, P., Narkar, K.: Contact stress analysis of kiln tyre and thrust roller by using normal loading. Int. Eng. Res. J. (IERJ), Special Issue 2 2728-2732 (2015)

17. Ling, Q., Yun, Z., Qiao, P., Identification of Rotary Kiln Cylinder Bending by Using Wavelet. Taylor \& Francis Group, London, Materials Science and Engineering Applications Lei, Xu \& Zhang (2017)

18. Xiao, Y.-G., Pan, D.-F., Lei, X.-M.: Contact pressure distribution and support angle optimization of kiln tyre. J. Central South Univ. Technol. 13(3), 246-250 (2006)

19. Abd El-Raheem, A.: Optimal plans and estimation of constantstress accelerated life tests for the extension of the exponential distribution under type-I censorin (2019)

Publisher's Note Springer Nature remains neutral with regard to jurisdictional claims in published maps and institutional affiliations. 